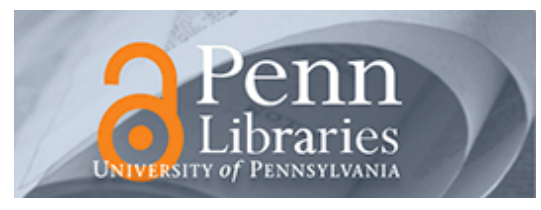

University of Pennsylvania

ScholarlyCommons

Marketing Papers

Wharton Faculty Research

1996

\title{
The Effects of Pictorial Realism, Delay of Visual Feedback, and Observer Interactivity on the Subjective Sense of Presence
}

Robert B. Welch

Theodore T. Blackmon

Andrew Liu

Barbara A. Mellers

University of Pennsylvania

Lawrence W. Stark

Follow this and additional works at: https://repository.upenn.edu/marketing_papers

Part of the Cognition and Perception Commons, Marketing Commons, Neurology Commons, Neurosciences Commons, Ophthalmology Commons, Optometry Commons, and the Psychiatry Commons

\section{Recommended Citation}

Welch, R. B., Blackmon, T. T., Liu, A., Mellers, B. A., \& Stark, L. W. (1996). The Effects of Pictorial Realism, Delay of Visual Feedback, and Observer Interactivity on the Subjective Sense of Presence. Presence: Teleoperators and Visual Environments, 5 (3), 263-273. http://dx.doi.org/10.1162/pres.1996.5.3.263

This paper is posted at ScholarlyCommons. https://repository.upenn.edu/marketing_papers/403

For more information, please contact repository@pobox.upenn.edu. 


\title{
The Effects of Pictorial Realism, Delay of Visual Feedback, and Observer Interactivity on the Subjective Sense of Presence
}

\author{
Abstract \\ Two experiments examined the effects of pictorial realism, observer interactivity, and delay of visual \\ feedback on the sense of "presence." Subjects were presented pairs of virtual enviornments (a simulated \\ driving task) that differed in one or more ways from each other. After subjects had completed the second \\ member of each pair they reported which of the two had produced the greater amount of presence and \\ indicated the size of this difference by means of a 1-100 scale. As predicted, realism and interactivity \\ increased presence while delay of visual feedback diminished it. According to subjects' verbal responses \\ to a postexperiment interview, pictorial realism was the least influential of the three variables examined. \\ Further, although some subjects reported an increase in the sense of presence over the course of the \\ experiment, most said it reamined unchanged or became weaker.

\section{Disciplines} \\ Business | Cognition and Perception | Marketing | Neurology | Neurosciences | Ophthalmology | Optometry \\ | Psychiatry
}




\section{Robert B. Welch'}

NASA-Ames Research Center

Mail Code 239-1I

Moffett Field, CA 94035

\section{Theodore T. Blackmon}

Andrew Liu' ${ }^{2}$

Barbara A. Mellers and Lawrence $\mathbf{W}$. Stark

Telerobotics and Neurology Units University of California Berkeley, CA 94720-2020

\section{The Effects of Pictorial Realism, Delay of Visual Feedback, and Observer Interactivity on the Subjective Sense of Presence}

\section{Introduction}

\section{I.I The Experience and Definition of Presence}

Despite knowledge to the contrary, users of virtual environments (VEs) often report feeling as if they are actually in the computer-generated world to which they are being exposed. This subjective state is often referred to as "presence" or "being there," and some investigators (e.g., Steuer, 1992) consider it to be the characteristic of "virtual reality" that most clearly distinguishes it from other forms of multimedia. ${ }^{3}$ In our view, presence is essentially the same as "telepresence," the experience reported by teleoperator users of being in the same distant physical location as the devices they are controlling.

It is proposed here that maximal presence/telepresence occurs when the user (1) feels immersed within the VE, (2) feels capable of moving about in it and manipulating its contents, and (3) has an intense interest in the interactive task (whether a work situation or a game). These, of course, are common events in the real world. Indeed, the development of VEs can be viewed as an attempt to produce, by means of a computer program and accompanying hardware (e.g., a DataGlove), the same experiences of clarity, completeness, vivacity, continuity, constancy, and presence that occur in normal perception (e.g., Stark, 1994).

1. The order of authorship, after the senior author, is alphabetical.

2. Now at Nissan Cambridge Basic Research, Cambridge, MA.

3. For the remainder of this paper the phrase "virtual reality" will be eschewed in favor of "virtual environment," as we consider the former to be oxymoronic and thus meaningless. 
Despite the preceding attempt, it is premature to think that one can formulate an exact and final definition of presence. Such certainty awaits the outcome of many experiments such as the present ones in which potentially important variables are manipulated and their effects on presence assessed. On the other hand, unless investigators have at least a rudimentary grasp of the concept, they will be unable to study it. Likewise, subjects in such experiments must be provided with a general idea or description of what it is they are to report or else they will not know what to do. Finally, even if experimenters do hold a very precise definition of presence, it is probably inadvisable to communicate it to their subjects before testing them because, by so doing, they may strongly suggest to them the effects that particular independent variables "ought" to have. For example, if subjects were informed that presence refers to the feeling of being surrounded by an unbroken visual world, it would come as no great surprise, and indeed would be tautological, to find that when these subjects view a VE through a $360^{\circ}$ head-mounted display (HMD), they report more presence than when they view the same VE on a flat TV monitor.

Although there has been much discussion about the nature, genesis, and modification of presence (Barfield \& Hendrix, 1995; Barfield \& Weghorst, 1993; Barfield, Zeltzer, Sheridan, \& Slater, 1995; Fontaine, 1992; Heeter, 1992; Held \& Durlach, 1992; Loomis, 1992; Sheridan, 1992; Slater \& Usoh, 1992; Slater, Usoh, \& Steed, 1994; Steuer, 1992; Zeltzer, 1992), very little in the way of controlled, quantitative research has been published testing these ideas. Furthermore, the common belief that presence improves performance has not been investigated adequately. Clearly, to address either of these issues one must first have a way to measure presence.

\section{I.2 The Measurement of Presence}

Presence, like other subjective mental states, can be measured either behaviorally or introspectively, using self-report (although the latter is also a form of behavior). Included in the first category are motor reflexes (e.g., flinching) and neurophysiological responses (e.g., arousal). For example, if a VE presents observers with a rapidly approaching object and they blink, turn away, and undergo a sudden increase in heart rate, it is reasonable to conclude that they have experienced a strong sense of presence. Examples of self-report measures include Likert (e.g., 1-7) rating scales and direct magnitude estimates (e.g., Stevens, 1957), by which VE users can indicate the degree of presence they are experiencing. Neither of the two types of measures is sufficient by itself, however. It is possible, for example, to imagine reports of presence without their expected behavioral concomitants and vice versa. Ideally, then, one should employ both measures in order to avoid the limitations of either by itself.

\section{I.3 Factors Potentially Affecting Presence}

Heeter (1992) has argued for three different kinds of presence: environmental, social, and individual. We believe, however, that it is more parsimonious to view presence as a single (albeit multidimensional) entity that is influenced by many different variables, all or most of which can be neatly categorized by Heeter's tripartite system.

Environmental factors that might affect presence are (1) the range of sensory experiences and/or modalities stimulated, (2) the amount of sensory resolution (e.g., pixel density), (3) the degree of similarity between the observer's body (e.g., the hand) and its visual representation, (4) the presence or absence of stereopsis, (5) black and white versus color presentation, (6) the presence or absence of perceptual constancy during movements of the body and/or sensory organs, and (7) the familiarity of the scene. It seems likely that the greater the number of sensory systems engaged, the more sensory information provided, and the more realistically the sensory environment is represented, the greater the presence experienced.

Potentially important social factors are (1) whether other (simulated) individuals are present in the VE and (2) the extent to which these others respond to or interact with the primary observer. Here one might predict that exposure to other virtual actors, especially 
ones that react to the existence and actions of the primary observer, will increase presence (e.g., Steuer, 1992).

Finally, individual factors include, but are certainly not limited to ( 1 ) the assumptions that observers bring to the VE, (2) the amount of practice they have had on the VE task (assuming there is one), (3) the length of their exposure to and/or interaction with the VE, (4) the degree to which they have become familiar with (and perhaps adapted to) the intersensory and sensorimotor discordances that may be present, and (5) individual predispositions to rely on or attend to one sensory modality (e.g., vision) over another (e.g., audition; Slater \& Usoh, 1993). The effects predicted for these variables are not always obvious. For example, it is uncertain (to the present authors, at least) if presence should increase, decrease, or stay the same with continued exposure to the VE.

Despite the wide array of variables postulated to play a role in presence, the research literature to date provides few relevant well-controlled, quantitative studies (Barfield \& Hendrix, 1995; Slater \& Usoh, 1993; Slater, Usoh, \& Steed, 1994). Clearly, then, there is need for a systematic examination of these factors, and an assessment of their relative importance.

\section{I.4 The Present Studies}

In the present investigation, subjects were exposed to all possible pairings of a series of VEs involving an automobile driving task. For each pair they were to indicate which member produced the greater amount of presence. This is the "Method of Paired Comparisons" (e.g., Birnbaum, 1978; Cohn, 1894), a procedure with a long and distinguished history in the area of psychological scaling. Experiment 1 examined the effects of (1) active (interactive) versus passive exposure to the $\mathrm{VE}$ and (2) pictorial realism. Experiment 2 examined the variable of delay of visual feedback and replicated the realism manipulation of Experiment 1. It was predicted, mainly on intuitive grounds, that presence would be increased by both pictorial realism and subject interactivity and decreased by delay of feedback.

\section{Experiment I: The Effects of Observer Interactivity and Pictorial Realism}

\section{I Method}

2.I.I Subjects. Twenty subjects (9 males and 11 females with an average age of 27.2 years) participated in the experiment. All were volunteers recruited from optometry classes at the University of California, Berkeley or from staff and engineering graduate students working in our laboratory. Half of the subjects were tested in one 2-week period and the remainder in a 2-week span about a year later. All subjects were naive about the driving task and the purpose of the experiment. One subject in the initial sample experienced mild nausea during testing and was replaced.

2.1.2 Basic Task and Apparatus. The visual scene as viewed by the subject is shown in the lower half of Figure 1. The task was to drive a simulated car as quickly and smoothly as possible through one lap of a winding road (Fig. 1, top half). Visual representations of other cars (not shown in the figure) periodically approached the subject's car in the opposite lane and one of his or her tasks was to avoid "colliding" with them. In the foreground was the crude outline of a car hood as it might appear through a windshield and beyond lay an extended view of the winding road (Fig. 1, bottom half). In the realistic VE, the remainder of the scene also contained hills, buildings, and guard posts (Fig. 1, bottom left).

The visual scene was rendered using threedimensional (3-D) computer graphics. A pair of stereoscopic images was presented sequentially to the subject's left and right eyes by means of a CrystalEyes (StereoGraphics, Inc.) display. Individual stereo ability was not tested, nor were subjects' interpupillary distances (IPDs) measured. Rather, a nominal IPD of $6.5 \mathrm{~cm}$ was assumed in the design of each scene. The simulation was developed in the Telerobotics Unit of the University of California, Berkeley and was rendered on a high-resolution CRT $(1280 \times 1024$ pixels $)$ of a Silicon Graphics, Inc. 4D/120 GTXB Graphics workstation. The geometric field of view (FOV) of the scene was defined in 

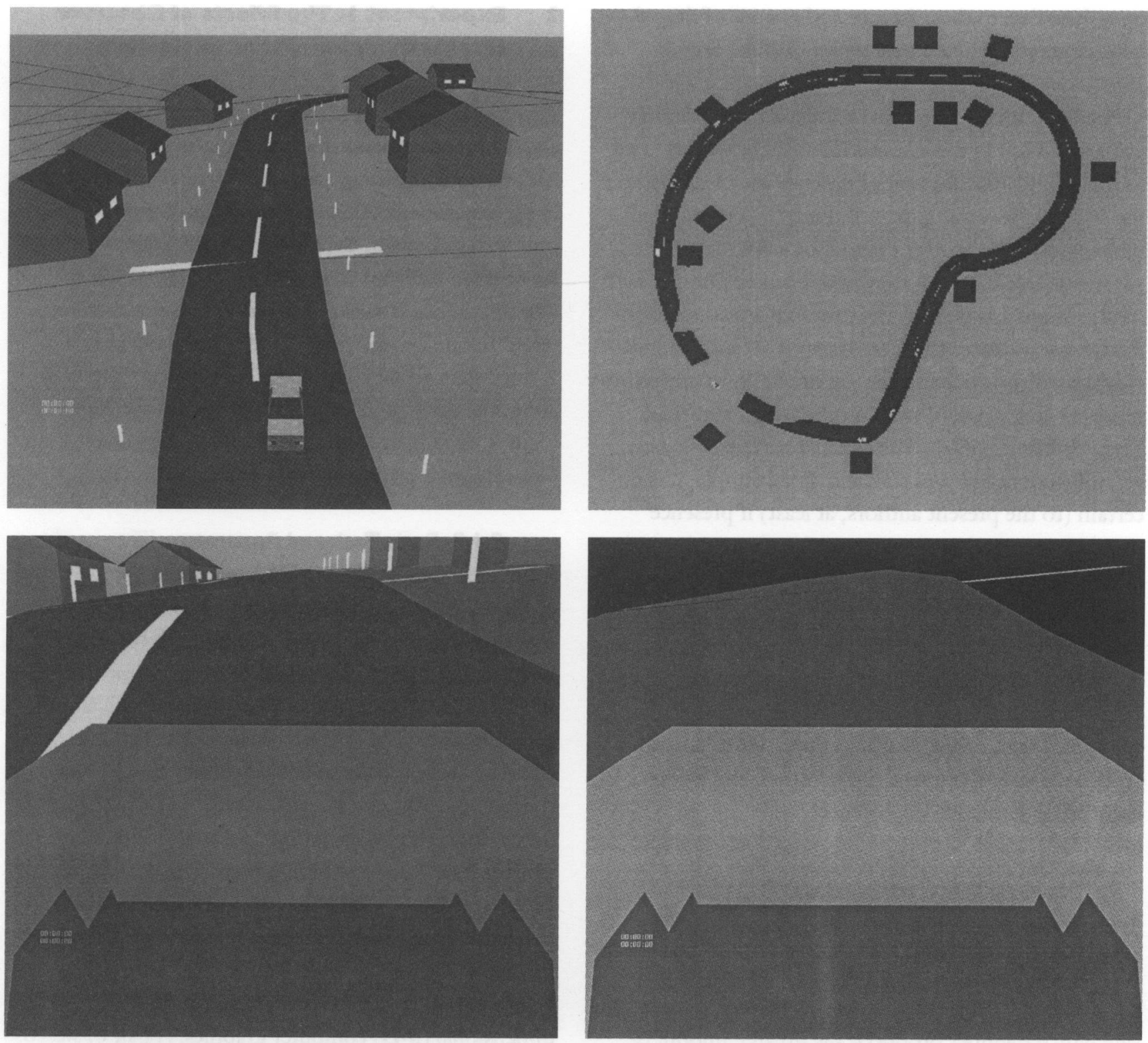

Figure I. Four views of the simulated driving scene (color not shown). Upper half shows a "God's eve" view of the car, the road with dashed medion lines, bordering white posts to provide motion cues, houses, and moderately hilly countryside. Two views from the driver's seat (bottom half) show the most and least pictorially realistic scenes (bottom left and bottom nght, respectively). which served as "anchors" for the $1-100$ presence scole. (See text for more detoll.)

graphics, using a horizontal viewing perspective of $62.5^{\circ}$. With a viewport having a horizontal width of 38 $\mathrm{cm}$ and the subject sitting at a viewing distance of 0.75 $\mathrm{m}$, the FOV on the subject's retina was approximately $27^{\circ}$.
During the experiment, the laboratory lights were extinguished and a curtain drawn around subjects to isolate them from the rest of the laboratory. A steering wheel and foot-operated accelerator and brake pedals allowed subjects to control the car's direction and speed, 
much as they would a real car. All input devices were connected to the SGI workstation through a 12-bit A/D board.

2.1.3 Experimental Design. Subjects were used as their own control in a $2 \times 2 \times 2$ factorial design in which the three factors were (1) subject interactivity, (2) pictorial realism, and (3) order of pairing. For the first factor, subjects acted either as the driver (active condition) or as the passenger (passive condition). The two levels of pictorial realism were

1. High realism - blue sky; hilly road surface and surround; green background; red farm houses; oncoming cars; guard posts.

2. Low realism-black sky; flat road surface and surround; black background; no peripheral objects; no oncoming cars.

\subsubsection{Definition and Measurement of Presence.} Subjects read the instructions from the CRT screen while the experimenter simultaneously read them aloud. The driving task was described and the general concept of presence was defined. Subjects were to indicate which of a given pair of VEs had produced the greater sense of presence and then to provide a number between 1 and 100 to represent the size of the perceived difference between them. The definition of presence emphasized the feeling that subjects were physically located in and surrounded by the portrayed visual world, rather than in the laboratory in which they knew the experiment to be taking place. The verbatim instructions were as follows:

"Immediately after you have driven in two of these worlds you will be asked to compare and choose between them. Please indicate to the experimenter in which of the two simulations you felt more physically located in the portrayed scene. That is, in which world did you more strongly feel that you were surrounded by the car and the outside world, rather than being in the laboratory in which this experiment is taking place. You will also be asked to estimate on a scale from 1 to 100 the perceived difference in your feeling of being physically located in the two worlds. A perceived difference of 1 means that your feeling of being physically located in each scene was about the same. A difference of 100 indicates that your feeling of being physically located in one world was much stronger than in the other world. As a reference point, assume that the difference in your feeling of being physically located in the two practice worlds has a value of $100 . "$

2.1.5 Procedure. Next, subjects engaged in two pairs of practice runs. The first pair consisted of an active condition in a more realistic scene (Fig. 1, lower left), and a passive condition in a scene with less realism (Fig. 1 , lower right). This pair was not actually used in the experiment, but served as the subjects' standard for the maximal difference (100) in presence between the two VEs, as indicated in the instructions above. It was assumed that the difference in perceived presence between these two practice scenes was as great or greater than would be experienced in any pair presented during the experiment proper. Here, as in the actual experiment, the subject was told before a run whether he or she would be a "driver" or a "passenger." The second pair of trials also entailed active and passive conditions, but did not differ quite as much in terms of pictorial realism as did the first pair. The two practice pairs provided subjects with some proficiency in the task, as well as practice making judgments of relative presence. Just before the actual experiment began, subjects were asked to verbalize their understanding of the concept of presence as it had been defined for them. If necessary, the concept was clarified further and questions (if any) were answered.

There were six possible pairings of the four interactivity/realism conditions and two orders. Each of these 12 combinations was presented twice, in pseudorandom order, for a grand total of 24 runs. After every other VE, the subject reported whether that VE had produced a greater or a lesser amount of presence than the preceding one and, according to the 1-100 scale, by how much.

On "active trials," subjects controlled the direction and speed of the car by means of the steering wheel and pedals; on "passive trials," they sat, hands on laps like a passenger, as the car "drove itself." A "yoked-control" procedure was used to equate visual experience in the two conditions. That is, the car's movements on a given active trial were recorded by the computer and then used 
to guide the car's movements on the next passive trial. Because it seemed likely that subjects would pay less attention to the visual scene when sitting passively than when playing the role of driver, they were instructed on each of the passive trials to count the number of oncoming cars and to report this number to the experimenter immediately after that trial. (Although subjects' responses on this task were recorded, their accuracy was not reported to them or used further.) Unfortunately, this is an imperfect control, as it cannot be claimed with confidence that the two conditions were perfectly equated in terms of mental workload or other cognitive factors. It should be pointed out, however, that such potential confounding is inherent in any experiment in which conditions of active (i.e., self-initiated) and passive (i.e., externally controlled) movement are compared (e.g., Held \& Hein, 1958).

After the last trial, subjects were quizzed about the amount of their previous experience with video games and automobile driving, the extent to which they were aware of the (unseen) laboratory during the experiment, the degree to which their sense of presence may have changed (and in which direction) over the course of the experiment, and their understanding of the concept of presence and how they were to report it. They were also asked to indicate to what extent each of the experimental variables seemed to them to have influenced their decisions about relative presence.

\subsection{Results}

According to the responses to the postexperiment interview, all the subjects understood our definition of presence and had guided their responses accordingly.

Table 1 presents the mean unscaled (la) and scaled (lb) 1-100 magnitude estimates for every pairing of the four VEs and for both orders. (A positive score indicates that the VE presented first was favored over the VE presented second; a negative score indicates the reverse.)

The magnitude estimates for each subject were scaled by means of the program MONANOVA (Kruskal, 1965) to eliminate individual biases in rating. These scaled estimates (Table $\mathrm{lb}$ ) were then used to compute the relative amount of presence in each display condi-
Table Ia. Experiment 1: Unscaled Ratings (I-100) for Active/Realistic (A/R), Passive/Realistic (P/R), Active/Unrealistic $(A / U)$, and Passive/Unrealistic (P/U) VEs

\begin{tabular}{ccccc}
\hline & \multicolumn{4}{l}{ VE presented first } \\
\cline { 2 - 5 } & $\mathrm{A} / \mathrm{R}$ & $\mathrm{P} / \mathrm{R}$ & $\mathrm{A} / \mathrm{U}$ & $\mathrm{P} / \mathrm{U}$ \\
\hline VE presented second & & & & \\
$\mathrm{A} / \mathrm{R}$ & - & -27.1 & -36.3 & -54.4 \\
$\mathrm{P} / \mathrm{R}$ & 23.6 & - & 1.3 & -53.6 \\
$\mathrm{~A} / \mathrm{U}$ & 27.3 & 65.0 & - & -29.3 \\
$\mathrm{P} / \mathrm{U}$ & 61.6 & 48.5 & 20.2 & - \\
\hline
\end{tabular}

Table Ib. Experiment 1: Scaled Ratings for Active/Realistic $(A / R)$, Passive/Realistic (P/R), Active/Unrealistic (A/U), and Passive/Unrealistic (P/U) VEs

\begin{tabular}{ccccc}
\hline \multicolumn{5}{c}{ VE presented first } \\
\cline { 2 - 5 } & $\mathrm{A} / \mathrm{R}$ & $\mathrm{P} / \mathrm{R}$ & $\mathrm{A} / \mathrm{U}$ & $\mathrm{P} / \mathrm{U}$ \\
\hline $\begin{array}{c}\text { VE presented } \\
\text { second }\end{array}$ & & & & \\
$\mathrm{A} / \mathrm{R}$ & - & -0.622 & -0.850 & -1.400 \\
$\mathrm{P} / \mathrm{R}$ & 0.459 & - & -0.493 & -1.190 \\
$\mathrm{~A} / \mathrm{U}$ & 0.897 & 0.378 & - & -0.681 \\
$\mathrm{P} / \mathrm{U}$ & 1.690 & 1.110 & 0.714 & - \\
\hline
\end{tabular}

tion. The MONANOVA program transforms the magnitude estimation data so that effects can be described with a simple linear model. The coefficients of the linear model reflect a scaled value of the amount of presence experienced in each VE. The corresponding scale values from each subject were pooled and averaged and, finally, tested by standard analysis of variance (ANOVA) techniques.

Values were subjected to a 2 (Interactivity) $\times 2$ (Realism) $\times 2$ (Order) within-subject ANOVA, according to which both Interactivity and Realism were statistically significant, $F(1,19)=14.00, p<0.001$, and $F(1,19)=$ $35.66, p<0.001$, respectively. Order was not statistically significant, $F(1,19)<1.0$. Finally, none of the interactions was significant. Examination of the mean 
Table 2. Responses to the Postexperiment Questionnaire

1. What was more important to you in making your decision, how realistic the scene looked or having control over the car/delay of visual feedback?

\begin{tabular}{|c|c|c|c|}
\hline & $\begin{array}{l}\text { Pictorial } \\
\text { realism } \\
(\%)\end{array}$ & $\begin{array}{l}\text { Control over car } \\
\text { (Expt. 1)/ delay of } \\
\text { feedback (Expt. 2) } \\
(\%)\end{array}$ & $\begin{array}{l}\text { Both } \\
(\%)\end{array}$ \\
\hline Experiment 1 & 20 & 50 & 30 \\
\hline Experiment 2 & 6 & 89 & 5 \\
\hline \multicolumn{4}{|c|}{$\begin{array}{l}\text { 2. Did your sense of being in the scene increase, } \\
\text { decrease, or stay the same over the course of the } \\
\text { experiment? }\end{array}$} \\
\hline
\end{tabular}

\begin{tabular}{|c|c|c|c|c|c|}
\hline & $\begin{array}{l}\text { Increased } \\
(\%)\end{array}$ & \multicolumn{2}{|c|}{$\begin{array}{l}\text { Decreased } \\
(\%)\end{array}$} & \multicolumn{2}{|c|}{$\begin{array}{l}\text { Stayed the } \\
\text { same } \\
(\%)\end{array}$} \\
\hline Experiment 1 & 30 & 45 & & 25 & \\
\hline Experiment 2 & 28 & 29 & & 43 & \\
\hline \multicolumn{6}{|c|}{$\begin{array}{l}\text { 3. During the task, how aware of the laboratory envi- } \\
\text { ronment were you? }\end{array}$} \\
\hline & $\begin{array}{l}\text { Not } \\
\text { at all } \\
(\%)\end{array}$ & $\begin{array}{l}\text { Very } \\
\text { little } \\
(\%)\end{array}$ & $\begin{array}{l}\text { Somew } \\
(\%)\end{array}$ & & $\begin{array}{l}\text { Very } \\
\text { aware } \\
(\%)\end{array}$ \\
\hline Experiment 1 & 10 & 55 & 30 & & 5 \\
\hline Experiment 2 & 5 & 38 & 57 & & 0 \\
\hline
\end{tabular}

magnitude estimates indicates that, as expected, the Active/Realistic VE produced stronger presence than did the Passive/Non-Realistic VE (see, for example, the first column of Table la).

Responses to key postexperiment questions are presented in Table 2. It can be seen that subjects tended to believe that interactivity played a greater role than pictorial realism in their judgments of relative presence. When asked if the sense of presence had changed over the course of the experiment, there was a tendency to report a decrease. Finally, a majority of the subjects
(65\%) revealed that they were either unaware or only slightly aware of the laboratory environment during the experiment.

\section{Experiment 2: The Effects of Delay of Visual Feedback and Pictorial Realism}

\section{I Method}

3.1.I Subjects. Twenty subjects ( 9 males, 11 females; average age: 23.4 years) were drawn from the same population as in Experiment 1. Half were tested during one 3-week period and the remainder during a 2-week period about a year and a half later. All were naive about the task, visual displays, and purpose of the experiment. No subjects were lost to nausea or any other problems.

3.1.2 Basic Task and Apparatus. The task and apparatus were identical to those used in Experiment 1.

3.I.3 Experimental Design. Subjects were used as their own control in a $2 \times 2 \times 2$ factorial design, the three factors being (1) delay of visual feedback, (2) pictorial realism, and (3) order. The two levels of the first variable were (1) the shortest delay possible with our simulation (200-220 msec) and (2) an additional delay of $1.5 \mathrm{sec}$. The two levels of realism were the same as in Experiment 1.

3.1.4 Procedure and Measurement of Presence. The definition of presence and the instructions for driving the car and making the paired comparisons were nearly identical to those of Experiment 1 . In addition, subjects were warned that in some conditions they would experience a significant delay in the responsivity of their car and that, although this might cause them some difficulty in controlling the vehicle, they should continue to do the best they could.

\subsection{Results}

The data, which were analyzed in the same manner as in Experiment 1, are presented in Table 3. According 
Table 3a. Experiment 2: Unscaled Ratings $(1-100)$ for No-Delay/Realistic (ND/R), Delay/Realistic (D/R), No-Delay/ Unrealistic (ND/U), and Delay/Unrealistic (D/U) VEs

VE presented first

$\mathrm{ND} / \mathrm{R} \quad \mathrm{D} / \mathrm{R} \quad \mathrm{ND} / \mathrm{U} \quad \mathrm{D} / \mathrm{U}$

\begin{tabular}{lrrrr} 
VE presented second & & & & \\
ND/R & - & -58.2 & -31.2 & -52.5 \\
D/R & 49.7 & - & 35.1 & -11.5 \\
ND/U & 13.1 & -36.2 & - & -32.5 \\
D/U & 55.3 & 20.1 & 52.3 & - \\
\hline
\end{tabular}

Table 3b. Experiment 2: Scaled Ratings for No-Delay/Realistic (ND/R), Delay/Realistic (D/R), No-Delay/Unrealistic (ND/U), and Delay/Unrealistic (D/U) VEs

\begin{tabular}{lcccc}
\hline \multicolumn{5}{c}{ VE presented first } \\
\cline { 2 - 5 } & $\mathrm{ND} / \mathrm{R}$ & $\mathrm{D} / \mathrm{R}$ & $\mathrm{ND} / \mathrm{U}$ & $\mathrm{D} / \mathrm{U}$ \\
\hline $\begin{array}{c}\text { VE presented } \\
\text { second }\end{array}$ & & & & \\
$\mathrm{ND} / \mathrm{R}$ & - & -1.563 & -0.531 & -1.560 \\
$\mathrm{D} / \mathrm{R}$ & 1.275 & - & 0.907 & -0.109 \\
$\mathrm{ND} / \mathrm{U}$ & 0.365 & -0.819 & - & -1.050 \\
$\mathrm{D} / \mathrm{U}$ & 1.579 & 0.273 & 1.220 & - \\
\hline
\end{tabular}

to a 2 (Feedback Delay) $\times 2$ (Realism) $\times 2$ (Order $)$ within-subject ANOVA, both Delay, $F(1,19)=30.94$, $p<0.001$, and Realism, $F(1,19)=4.52, p=0.047$, were statistically significant, while Order was not, $F(1$, $19)<1.0$. None of the interactions was significant. As predicted, the No-Delay/Realistic VE produced more presence than the Delayed/Unrealistic VE (see, for example, the first column of Table $3 a$ ).

It can be seen from Table 2 that the vast majority of subjects (89\%) believed that delay of feedback was more important than pictorial realism in influencing their experience of presence, which is congruent with the results of the statistical analysis above. Some subjects reported that presence increased in strength over the course of the experiment, while others reported a decrease or no change. Finally, the most common response to the question concerning awareness of the laboratory was "somewhat" (57\%).

\section{General Discussion and Conclusions}

\section{I Findings}

The results of both experiments were encouraging in that the variables examined had the predicted effects. Thus, presence was enhanced by pictorial realism (Experiments 1 and 2) and interactivity (Experiment 1 ), while it was attenuated by delay of visual feedback (Experiment 2).

4.I.I Pictorial Realism. In both experiments, subjects' responses to the postexperiment interview suggested that pictorial realism played less of a role in judgments of presence than did interactivity (Experiment 1 ) or delay of feedback (Experiment 2). In a preliminary study in which realism was the only independent variable we also found a weak effect. Contrary to the present results, however, that study revealed a main effect of order of presentation of the VEs, suggesting that in the present experiments the effect of order may have been masked by the presence of more "powerful" variables.

It is not surprising perhaps that pictorial realism appeared to have little effect on presence since it would seem likely that even a completely unfamiliar environment (e.g., a room filled with random dots) could produce a strong sense of presence or, alternatively, that a crudely drawn but familiar scene could greatly detract from it. Further complicating the situation is the problem of defining pictorial realism. For example, it could be justifiably claimed that the two levels of this ostensible variable in the present experiment actually represented a difference in complexity. If this is a correct assessment, then an unconfounded examination of this variable will require keeping complexity constant while varying the degree to which the graphic representation is similar to the "real world." This would seem to be a very difficult manipulation to effect. 
4.1.2 Interactivity. Because of the 200- to 220msec visual feedback delay inherent in our VE system, it was not self-evident that presence would be stronger when the subjects controlled their car than when they served as passengers. That is, one might well have predicted that this delay, which, of course, could be detected by subjects only when they had control of the car's movements, would diminish the sense of presence (as found in Experiment 2) over that experienced in the passive exposure condition. Apparently, the act of controlling the car increased the subjective sense of presence more than the delay of visual feedback decreased it.

4.1.3 Delay of Visual Feedback. The finding that an additional delay of visual feedback reduced the strength of presence confirms the suspicions of Held and Durlach (1992), who had predicted such an effect on the basis of the work by Held, Efstathiou, and Greene (1966) on adaptation to prismatically displaced vision. It seems quite reasonable that the sense of presence would depend heavily on the perception of one's ability to move independently through the environment, an experience to which a delay of visual feedback is obviously inimical.

4.1.4 Continued Exposure. As indicated previously, it is not apparent what effect continued or repetitive exposure to a VE should have on presence. Protracted exposure has many potential concomitants, including increased task familiarity, decreased anxiety, boredom, reduced novelty, sensitization to intersensory discrepancies, and adaptation to these discrepancies. Some of these potential factors might be expected to increase the sense of presence, while others are likely to reduce it, so it is unclear what the net effect will be. Thus, it is interesting to note that in both of the present experiments subjects typically reported that their sense of presence remained unchanged or even decreased over the course of the experiment (Table 2).

\subsection{Problems and Issues}

4.2.1 Defining Presence for Subjects. According to the postexperiment interviews, all subjects in both experiments understood what we meant by presence and how they were to report it. However, a potentially serious problem exists in this regard. Specifically, our use of the two (presumably) most different practice VEs as the standard by which subjects were to anchor their 1-100 difference-of-presence scale (see lower half of Fig. 1) might have biased them to respond in accord with the implicit task demands that this procedure entailed. This problem (along with that of providing subjects with an overly explicit definition of presence, as described earlier) must be avoided in future research.

Of course, presence might be measured differently than was the case here. One alternative we are currently examining is magnitude estimation in which subjects use a $0-100 \%$ scale to compare (1) a VE that they are experiencing (or have just experienced) to (2) a corresponding physical (real) situation. Clearly, the latter will elicit maximal presence (by definition), and thus it is reasonable for the experimenter to assign it a value of $100 \%$. Given this "anchor" to the real world, one could expect subjects to provide a lesser percentage of presence for the related VE, except in the unlikely (but profoundly interesting) event that they cannot distinguish that VE from reality. One important advantage of this measure over the Method of Paired Comparisons is that it provides an absolute, rather than a relative, measure of presence.

\subsubsection{The Relative Weighting of Factors. It is} not easy to determine the relative importance of different factors in the elicitation and modification of presence because the conclusion one draws will depend heavily on the levels of each variable chosen for examination. For example, it is possible to attribute the present finding of a much greater effect for delay of feedback than for realism (Experiment 2), not to an inherent difference in the importance of these variables, but to the possibility that the two levels of delay (200-220 msec versus $1.5 \mathrm{sec}$ ) used in the present experiment differed functionally from each other much more than did the two levels of realism.

Further complicating matters is the likelihood that the effect of a given variable on presence will vary greatly as a function of the task in which the subject is engaging. Thus, delay of feedback should be expected to interfere greatly with presence when the subject's task is that of 
driving a car (as in the present studies), but very little if their goal is, for example, to identify faces.

Possible ways to obtain more definitive evidence of the importance of two (or more) factors in presence include (1) "trade-off" experiments, in which the investigator measures the extent to which one variable must be changed to offset the effect of a second variable,

(2) comparing the two variables in question in terms of equal "just noticeable differences" (JNDs), and

(3) equating the two variables by means of cross-modality matching. We plan to use one or more of these procedures in future research.

4.2.3 Technological Limitations. The technology used to create our VEs suffered from several deficiencies. First, in contrast to many other VE systems, ours did not entail an HMD, but rather a CRT that subjects viewed as they would a television set. However, in its defense, our procedure did provide subjects with stereoscopic vision, required them to sit relatively close to the screen, and shielded them from the rest of the laboratory by a curtain. Nevertheless, a sizable number of subjects in each experiment reported at least some awareness of the laboratory during the experiment (see Table 2). Thus, because our situation was clearly not as immersive as it could have been, the absolute level of presence experienced by our subjects may have been relatively low. Of course, our use of comparative judgments makes it impossible either to confirm or disconfirm this suspicion. To rectify this situation, the viewer in our future studies will wear an HMD and move about within the virtual world while presence is measured by means of the magnitude estimation procedure described above. Another limitation of our VEs was the presence of a 200-220 msec delay in visual feedback in our socalled "no-delay" conditions, a problem that the use of faster computers will eliminate.

4.2.4 Why Study Presence? It is legitimate to ask why a scientist should be interested in presence in the first place. It could be argued, for example, that presence is merely an epiphenomenon of a, $\mathrm{VE}$ and therefore of little importance (except presumably for the entertainment industry). However, we believe that there are sev- eral reasons why it is useful to understand presence. First, it may be true, as commonly suggested, that presence facilitates task performance. Unfortunately, this reasonable-sounding hypothesis is extremely difficult to test because many of the variables that may increase presence (greater pixel density, reduced delay of feedback, etc.) are also likely to facilitate task performance even if there is no causal link between the two events. Thus, although it is likely that presence and performance are related in some way, it is not clear if this relationship is causal or correlational or, in either case, how strong it is. It is mandatory therefore for studies of the putative presence-performance relationship to use stimulus (or other) manipulations of presence that do not, in and of themselves, directly influence performance.

A related reason why the measurement and manipulation of presence should be of interest is the possibility that, even if it does not have a direct impact on performance, its occurrence in a given VE (or teleoperator system) will have the effect of maintaining or even increasing the users' attention and motivation, which, in turn, is likely to facilitate performance (and perhaps transfer of training as well).

A final reason for being interested in the psychological phenomenon of presence, and the one closest to our hearts, is that an understanding of this experience as it occurs in VEs should elucidate the same phenomenon in real environments, an important but thus far seriously neglected aspect of human perception.

\section{Acknowledgments}

The present research was supported, in part, by a Cooperative Agreement (NCC2-757) between NASA-Ames Research Center and the University of California, Berkeley. We wish to thank Marcel Wierda of the Traffic Research Center, University of Groningen, The Netherlands, and Kosuke Yotsuzuka of the Engineering Research Laboratories, Toray Industries, Inc., Otsu, Shiga, Japan, who developed the virtual driving task, and Theresa Ngyuen, Cary Tseng, and Steven Weekes of the University of California, Berkelely, who tested subjects in the experiments. Finally, we thank Drs. Malcolm M. Cohen, Lawrence Guzy, and Heiko Hecht, and the anonymous re- 
viewers, all of whose comments on earlier drafts of this paper significantly improved both the final manuscript and our thinking.

\section{References}

Barfield, W., \& Hendrix, C. (1995). Factors affecting presence and performance in virtual environments. In R. M. Satava, K. Morgan, H. B. Sieburg, R. Mattheus, \& J. P. Christensen (Eds.). Interactive technology and the new paradigm for healthcare (pp. 21-28). Washington, DC: IOS Press.

Barfield, W., \& Weghorst, S. (1993). The sense of presence within virtual environments: A conceptual framework. In G. Salvendy \& M. J. Smith (Eds.), Human-computer interaction: Software and hardware interfaces. Amsterdam: Elsevier.

Barfield, W., Zeltzer, D., Sheridan, T., \& Slater, M. (1995). Presence and performance within virtual environments. In W. Barfield \& T. Furness (Eds.), Virtual environments and advanced interface design. New York: Oxford, 473-513.

Birnbaum, M. H. (1978). Differences and ratios in psychological measurement. In N. J. Castellan \& F. Restle (Eds.), Cognitive theory (Vol. 3, pp. 33-74). Hillsdale, NJ: Lawrence Erlbaum.

Cohn, J. (1894). Experimentelle Untersuchungen uber die Gefuhlsbetonung der Farben, Helligkeiten, and ihrer Combinationen. Philosophische Studien, 10, 526-603.

Fontaine, G. (1992). The experience of a sense of presence in intercultural and international encounters. Presence: Teleoperators and Virtual Environments, 1, 482-490.

Heeter, C. (1992). Being there: The subjective experience of presence. Presence: Teleoperators and Virtual Environments, 1, 262-271.

Held, R., \& Durlach, N. (1992). Telepresence. Presence: Teleoperators and Virtual Environments, 1, 109-112.

Held, R., Efstathiou, A., \& Greene, M. (1966). Adaptation to displaced and delayed visual feedback from the hand. Journal of Experimental Psychology, 72, 887-891.

Held, R., \& Hein, A. (1958). Adaptation to disarranged handeye coordination contingent upon reafferent stimulation, Perceptual and Motor Skills, 8, 87-90.

Kruskal, J. B. (1965). Analysis of factorial experiments by estimate monotone transformations of the data. Journal of the Royal Statistical Society, Series B, 27, 251-263.

Loomis, J. M. (1992). Distal attribution and presence. Presence: Teleoperators and Virtual Environments, 1, 113-119.

Navas, F., \& Stark, L. (1968). Sampling or intermittency in the hand control system. Biophysical Journal, 8, 252-301.

Sheridan, T. B. (1992). Musings on telepresence and virtual presence. Presence: Teleoperators and Virtual Environments, 1 , 120-126.

Slater, M., \& Usoh, M. (1993). Representative systems, perceptual position and presence in virtual environments. Presence: Teleoperators and Virtual Environments, 2, 221-233.

Slater, M., Usoh, M., \& Steed, A. (1994). Depth of presence in virtual environments. Presence: Teleoperators and Virtual Environments, 3, 130-144.

Stark, L. W. (1994, July). Why virtual reality works: Topdown vision in humans and robots. In ICAT '94 Proceedings: The Fourth International Conference on Artificial Reality and Tele-Existence, Tokyo.

Steuer, J. (1992). Defining virtual reality: Dimensions determining telepresence. Journal of Communication, 42, 73-93.

Stevens, S. S. (1957). On the psychophysical law. Psychological Review, 64, 153-181.

Young, L. R., \& Stark, L. (1963). Variable feedback experiments testing a sampled data model for eye tracking movements. IEEE Transactions on Human Factors in Electronics, HFE-4, 38-51.

Zeltzer, D. (1992). Autonomy, interaction, and presence. Presence: Teleoperators and Virtual Environments, 1, 127-132. 
This article has been cited by:

1. B. Keshavarz, R. Ramkhalawansingh, B. Haycock, S. Shahab, J.L. Campos. 2018. Comparing simulator sickness in younger and older adults during simulated driving under different multisensory conditions. Transportation Research Part F: Traffic Psychology and Behaviour 54, 47-62. [Crossref]

2. Alice Chirico, Francesco Ferrise, Lorenzo Cordella, Andrea Gaggioli. 2018. Designing Awe in Virtual Reality: An Experimental Study. Frontiers in Psychology 8. . [Crossref]

3. Richard Skarbez, Frederick P. Brooks, Jr., Mary C. Whitton. 2017. A Survey of Presence and Related Concepts. ACM Computing Surveys 50:6, 1-39. [Crossref]

4. Alexander Smolentsev, Jessica E. Cornick, Jim Blascovich. 2017. Using a preamble to increase presence in digital virtual environments. Virtual Reality 21:3, 153-164. [Crossref]

5. Jonatan Hvass, Oliver Larsen, Kasper Vendelbo, Niels Nilsson, Rolf Nordahl, Stefania Serafin. Visual realism and presence in a virtual reality game $1-4$. [Crossref]

6. Lance Putnam, William Latham, Stephen Todd. 2017. Flow Fields and Agents for Immersive Interaction in Mutator VR: Vortex. Presence: Teleoperators and Virtual Environments 26:2, 138-156. [Abstract] [PDF] [PDF Plus]

7. Ilias Bergstrom, Sergio Azevedo, Panos Papiotis, Nuno Saldanha, Mel Slater. 2017. The Plausibility of a String Quartet Performance in Virtual Reality. IEEE Transactions on Visualization and Computer Graphics 23:4, 1352-1359. [Crossref]

8. James J. Cummings, Jeremy N. Bailenson. 2016. How Immersive Is Enough? A Meta-Analysis of the Effect of Immersive Technology on User Presence. Media Psychology 19:2, 272-309. [Crossref]

9. Andrea Jelić, Gaetano Tieri, Federico De Matteis, Fabio Babiloni, Giovanni Vecchiato. 2016. The Enactive Approach to Architectural Experience: A Neurophysiological Perspective on Embodiment, Motivation, and Affordances. Frontiers in Psychology 7. . [Crossref]

10. Evelyne Lombardo, Christophe Guion, Joaquin Keller. Study of a Virtual Conference in a Mirror World with Avatars and HMD 330-338. [Crossref]

11. Benson G. Munyan, Sandra M. Neer, Deborah C. Beidel, Florian Jentsch. Olfactory Stimuli Increase Presence During Simulated Exposure 164-172. [Crossref]

12. Ioannis Ntokas, Vicky Maratou, Michalis Xenos. Usability and presence evaluation of a 3D virtual world learning environment simulating information security threats 71-76. [Crossref]

13. Jordan Smith. 2015. Immersive Virtual Environment Technology to Supplement Environmental Perception, Preference and Behavior Research: A Review with Applications. International Journal of Environmental Research and Public Health 12:9, 11486-11505. [Crossref]

14. Peter Fromberger, Sabrina Meyer, Christina Kempf, Kirsten Jordan, Jürgen L. Müller. 2015. Virtual Viewing Time: The Relationship between Presence and Sexual Interest in Androphilic and Gynephilic Men. PLOS ONE 10:5, e0127156. [Crossref]

15. Andrea Martina, Andrea Bottino, Irene Rubino, Daniel Cook. 2015. One Day at the Sands: Exploring Las Vegas' Intangible Heritage through Virtual Reality. International Journal of Heritage in the Digital Era 4:1, 1-19. [Crossref]

16. David Weibel, Jan Schmutz, Olivier Pahud, Bartholomäus Wissmath. 2015. Measuring Spatial Presence: Introducing and Validating the Pictorial Presence SAM. Presence: Teleoperators and Virtual Environments 24:1, 44-61. [Abstract] [PDF] [PDF Plus]

17. Brian Simpson, Jeffrey Cowgill, Robert Gilkey, Janet Weisenberger. Technological Considerations in the Design of Multisensory Virtual Environments: How Real Does It Need to Be? 313-333. [Crossref]

18. Behrang Keshavarz, Heiko Hecht, Ben Lawson. Visually Induced Motion Sickness: Causes, Characteristics, and Countermeasures 647-698. [Crossref]

19. Li-Keng Cheng, Ming-Hua Chieng, Wei-Hua Chieng. 2014. Measuring virtual experience in a three-dimensional virtual reality interactive simulator environment: a structural equation modeling approach. Virtual Reality 18:3, 173-188. [Crossref]

20. Kwanguk Kim, M. Zachary Rosenthal, David J. Zielinski, Rachael Brady. 2014. Effects of virtual environment platforms on emotional responses. Computer Methods and Programs in Biomedicine 113:3, 882-893. [Crossref]

21. Raquel Viciana-Abad, Arcadio Reyes-Lecuona, Alejandro Rosa-Pujazón, José Manuel Pérez-Lorenzo. 2014. The influence of different sensory cues as selection feedback and co-location in presence and task performance. Multimedia Tools and Applications 68:3, 623-639. [Crossref] 
22. Armando Cruz, Hugo Paredes, Benjamim Fonseca, Leonel Morgado, Paulo Martins. 2014. Can Presence Improve Collaboration in 3D Virtual Worlds?. Procedia Technology 13, 47-55. [Crossref]

23. Guy Wallis, Jennifer Tichon. 2013. Predicting the Efficacy of Simulator-based Training Using a Perceptual Judgment Task Versus Questionnaire-based Measures of Presence. Presence: Teleoperators and Virtual Environments 22:1, 67-85. [Abstract] [PDF] [PDF Plus]

24. Antal Haans, Wijnand A. IJsselsteijn. 2012. Embodiment and telepresence: Toward a comprehensive theoretical framework. Interacting with Computers 24:4, 211-218. [Crossref]

25. Astrid M. von der Pütten, Jennifer Klatt, Simon Ten Broeke, Roderick McCall, Nicole C. Krämer, Richard Wetzel, Lisa Blum, Leif Oppermann, Johannes Klatt. 2012. Subjective and behavioral presence measurement and interactivity in the collaborative augmented reality game TimeWarp. Interacting with Computers 24:4, 317-325. [Crossref]

26. Sangwon Bae, Haein Lee, Hyejin Park, Hanju Cho, Joonah Park, Jinwoo Kim. 2012. The effects of egocentric and allocentric representations on presence and perceived realism: Tested in stereoscopic 3D games. Interacting with Computers 24:4, 251-264. [Crossref]

27. Claudia Schrader, Theo J. Bastiaens. 2012. The influence of virtual presence: Effects on experienced cognitive load and learning outcomes in educational computer games. Computers in Human Bebavior 28:2, 648-658. [Crossref]

28. Jun'ichiro Seyama, Ruth S. Nagayama. 2011. Photorealism aftereffect. Psychological Researcb 75:3, 179-187. [Crossref]

29. Ivan Alsina-Jurnet, José Gutiérrez-Maldonado. 2010. Influence of personality and individual abilities on the sense of presence experienced in anxiety triggering virtual environments. International Journal of Human-Computer Studies 68:10, 788-801. [Crossref]

30. Sana Debbabi, Mohamed Daassi, Serge Baile. 2010. Effect of online 3D advertising on consumer responses: the mediating role of telepresence. Journal of Marketing Management 26:9-10, 967-992. [Crossref]

31. Nicolas Vignais, Richard Kulpa, Cathy Craig, Sébastien Brault, Franck Multon, Benoit Bideau. 2010. Influence of the Graphical Levels of Detail of a Virtual Thrower on the Perception of the Movement. Presence: Teleoperators and Virtual Environments 19:3, 243-252. [Abstract] [PDF] [PDF Plus] [Supplemental Material]

32. Russell M. Taylor, II, Jason Jerald, Chris VanderKnyff, Jeremy Wendt, David Borland, David Marshburn, William R. Sherman, Mary C. Whitton. 2010. Lessons about Virtual Environment Software Systems from 20 Years of VE Building. Presence: Teleoperators and Virtual Environments 19:2, 162-178. [Abstract] [PDF] [PDF Plus] [Supplemental Material]

33. Beatriz Rey, Mariano Alcañiz, José Tembl, Vera Parkhutik. 2010. Brain activity and presence: a preliminary study in different immersive conditions using transcranial Doppler monitoring. Virtual Reality 14:1, 55-65. [Crossref]

34. Bartholomäus Wissmath, David Weibel, Fred W. Mast. 2010. Measuring presence with verbal versus pictorial scales: a comparison between online- and ex post-ratings. Virtual Reality 14:1, 43-53. [Crossref]

35. M. Carmen Juan, David Pérez. 2009. Comparison of the Levels of Presence and Anxiety in an Acrophobic Environment Viewed via HMD or CAVE. Presence: Teleoperators and Virtual Environments 18:3, 232-248. [Abstract] [PDF] [PDF Plus]

36. H.L. Woo. 2009. Designing multimedia learning environments using animated pedagogical agents: factors and issues. Journal of Computer Assisted Learning 25:3, 203-218. [Crossref]

37. Sangyoon Lee, Gerard Jounghyun Kim. 2008. Effects of haptic feedback, stereoscopy, and image resolution on performance and presence in remote navigation. International Journal of Human-Computer Studies 66:10, 701-717. [Crossref]

38. Sungkil Lee, Gerard Jounghyun Kim. 2008. Effects of visual cues and sustained attention on spatial presence in virtual environments based on spatial and object distinction. Interacting with Computers 20:4-5, 491-502. [Crossref]

39. Stéphane Bouchard, Julie St-Jacques, Geneviève Robillard, Patrice Renaud. 2008. Anxiety Increases the Feeling of Presence in Virtual Reality. Presence: Teleoperators and Virtual Environments 17:4, 376-391. [Abstract] [PDF] [PDF Plus]

40. Karsten Bormann. 2008. Visuals are not what they look. Virtual Reality 12:2, 115-123. [Crossref]

41. Yoonhyuk Jung. Influence of Sense of Presence on Intention to Participate in a Virtual Community 325-325. [Crossref]

42. Cees J. H. Midden, Florian G. Kaiser, L. Teddy McCalley. 2007. Technology's Four Roles in Understanding Individuals' Conservation of Natural Resources. Journal of Social Issues 63:1, 155-174. [Crossref]

43. Sangyoon Lee, Tian Chen, Jongseo Kim, Gerard Jounghyun Kim, Sung Ho Han, Zhigeng Pan. 2007. Effects of Tactile Augmentation and Self-Body Visualization on Affective Property Evaluation of Virtual Mobile Phone Designs. Presence: Teleoperators and Virtual Environments 16:1, 45-64. [Abstract] [PDF] [PDF Plus]

44. Y.A.W. de Kort, A.L. Meijnders, A.A.G. Sponselee, W.A. IJsselsteijn. 2006. What's wrong with virtual trees? Restoring from stress in a mediated environment. Journal of Environmental Psychology 26:4, 309-320. [Crossref] 
45. Gerardo Herrera, Rita Jordan, Lucí Vera. 2006. Agency and Presence: A Common Dependence on Subjectivity?. Presence: Teleoperators and Virtual Environments 15:5, 539-552. [Abstract] [PDF] [PDF Plus]

46. Agneta Gulz, Magnus Haake. 2006. Design of animated pedagogical agents-A look at their look. International Journal of Human-Computer Studies 64:4, 322-339. [Crossref]

47. Ioannis Karaseitanidis, Angelos Amditis, Harshada Patel, Sarah Sharples, Evangelos Bekiaris, Alex Bullinger, Jolanda Tromp. 2006. Evaluation of virtual reality products and applications from individual, organizational and societal perspectives-The "VIEW" case study. International Journal of Human-Computer Studies 64:3, 251-266. [Crossref]

48. Y. Barniv, M. Aguilar, E. Hasanbelliu. 2005. Using EMG to Anticipate Head Motion for Virtual-Environment Applications. IEEE Transactions on Biomedical Engineering 52:6, 1078-1093. [Crossref]

49. Maria V. Sanchez-Vives, Mel Slater. 2005. From presence to consciousness through virtual reality. Nature Reviews Neuroscience 6:4, 332-339. [Crossref]

50. Jorge Santos, Natasha Merat, Sandra Mouta, Karel Brookhuis, Dick de Waard. 2005. The interaction between driving and invehicle information systems: Comparison of results from laboratory, simulator and real-world studies. Transportation Research Part F: Traffic Psychology and Behaviour 8:2, 135-146. [Crossref]

51. Andrea H. Mason, Christine L. MacKenzie. 2004. The Role of Graphical Feedback About Self-Movement when Receiving Objects in an Augmented Environment. Presence: Teleoperators and Virtual Environments 13:5, 507-519. [Abstract] [PDF] [PDF Plus]

52. Paul Van Schaik, Triece Turnbull, Anna Van Wersch, Sarah Drummond. 2004. Presence Within a Mixed Reality Environment. CyberPsychology \& Behavior 7:5, 540-552. [Crossref]

53. Wijnand IJsselsteijn, Yvonne de Kort, Joyce Westerink, Marko de Jager, Ronald Bonants. Fun and Sports: Enhancing the Home Fitness Experience 46-56. [Crossref]

54. Wooyoung Shim, Gerard Jounghyun Kim. 2003. Designing for Presence and Performance: The Case of the Virtual Fish Tank. Presence: Teleoperators and Virtual Environments 12:4, 374-386. [Abstract] [PDF] [PDF Plus]

55. John R. Wilson, Sarah C. Nichols. 2002. Measurement in virtual environments: another dimension to the objectivity/ subjectivity debate. Ergonomics 45:14, 1031-1036. [Crossref]

56. Kay M. Stanney, Kelly S. Kingdon, David Graeber, Robert S. Kennedy. 2002. Human Performance in Immersive Virtual Environments: Effects of Exposure Duration, User Control, and Scene Complexity. Human Performance 15:4, 339-366. [Crossref]

57. Holger Regenbrecht, Thomas Schubert. 2002. Real and Illusory Interactions Enhance Presence in Virtual Environments. Presence: Teleoperators and Virtual Environments 11:4, 425-434. [Abstract] [PDF] [PDF Plus]

58. Jinseok Seo, Gerard Jounghyun Kim. 2002. Design for Presence: A Structured Approach to Virtual Reality System Design. Presence: Teleoperators and Virtual Environments 11:4, 378-403. [Abstract] [PDF] [PDF Plus]

59. Henry Been-Lirn Duh, James J. W. Lin, Robert V. Kenyon, Donald E. Parker, Thomas A. Furness. 2002. Effects of Characteristics of Image Quality in an Immersive Environment. Presence: Teleoperators and Virtual Environments 11:3, 324-332. [Abstract] [PDF] [PDF Plus]

60. Yung Kyun Choi, Gordon E. Miracle, Frank Biocca. 2001. The Effects of Anthropomorphic Agents on Advertising Effectiveness and the Mediating Role of Presence. Journal of Interactive Advertising 2:1, 19-32. [Crossref]

61. Jane Lessiter, Jonathan Freeman, Edmund Keogh, Jules Davidoff. 2001. A Cross-Media Presence Questionnaire: The ITCSense of Presence Inventory. Presence: Teleoperators and Virtual Environments 10:3, 282-297. [Abstract] [PDF] [PDF Plus]

62. Thomas Schubert, Frank Friedmann, Holger Regenbrecht. 2001. The Experience of Presence: Factor Analytic Insights. Presence: Teleoperators and Virtual Environments 10:3, 266-281. [Abstract] [PDF] [PDF Plus]

63. Martijn J. Schuemie, Peter van der Straaten, Merel Krijn, Charles A.P.G. van der Mast. 2001. Research on Presence in Virtual Reality: A Survey. CyberPsychology \& Bebavior 4:2, 183-201. [Crossref]

64. Paul De Greef, Wijnand A. Ijsselsteijn. 2001. Social Presence in a Home Tele-Application. CyberPsychology \& Bebavior 4:2, 307-315. [Crossref]

65. James Anderson, Nahella Ashraf, Craig Douther, Mervyn A. Jack. 2001. Presence and Usability in Shared Space Virtual Conferencing: A Participatory Design Study. CyberPsychology \& Behavior 4:2, 287-305. [Crossref]

66. Wijnand A. Ijsselsteijn, Matthew Lombard, Jonathan Freeman. 2001. Toward a Core Bibliography of Presence. CyberPsycbology \& Bebavior 4:2, 317-321. [Crossref] 
67. Mel Slater, Anthony Steed. 2000. A Virtual Presence Counter. Presence: Teleoperators and Virtual Environments 9:5, 413-434. [Abstract] [PDF] [PDF Plus]

68. ROBERT M O'KEEFE, MELISSA COLE, PATRICK Y.K CHAU, ANN MASSEY, MITZI MONTOYA-WEISS, MARK PERRY. 2000. From the user interface to the consumer interface: results from a global experiment. International Journal of Human-Computer Studies 53:4, 611-628. [Crossref]

69. Jae Y. Jung, Bernard D. Adelstein, Stephen R. Ellis. 2000. Discriminability of Prediction Artifacts in a Time-Delayed Virtual Environment. Proceedings of the Human Factors and Ergonomics Society Annual Meeting 44:5, 499-502. [Crossref]

70. Craig D. Murray, Paul Arnold, Ben Thornton. 2000. Presence Accompanying Induced Hearing Loss: Implications for Immersive Virtual Environments. Presence: Teleoperators and Virtual Environments 9:2, 137-148. [Abstract] [PDF] [PDF Plus]

71. Jonathan Freeman, S. E. Avons, Ray Meddis, Don E. Pearson, Wijnand IJsselsteijn. 2000. Using Behavioral Realism to Estimate Presence: A Study of the Utility of Postural Responses to Motion Stimuli. Presence: Teleoperators and Virtual Environments 9:2, 149-164. [Abstract] [PDF] [PDF Plus]

72. SARAH NICHOLS, CLOVISSA HALDANE, JOHN R. WILSON. 2000. Measurement of presence and its consequences in virtual environments. International Journal of Human-Computer Studies 52:3, 471-491. [Crossref]

73. Robert B. Welch. 1999. How Can We Determine if the Sense of Presence Affects Task Performance?. Presence: Teleoperators and Virtual Environments 8:5, 574-577. [Abstract] [PDF] [PDF Plus]

74. Mel Slater. 1999. Measuring Presence: A Response to the Witmer and Singer Presence Questionnaire. Presence: Teleoperators and Virtual Environments 8:5, 560-565. [Citation] [PDF] [PDF Plus]

75. Stephen R. Ellis, Mark J. Young, Bernard D. Adelstein, Sheryl M. Ehrlich. 1999. Discrimination of Changes of Latency during Voluntary Hand Movement of Virtual Objects. Proceedings of the Human Factors and Ergonomics Society Annual Meeting 43:22, 1182-1186. [Crossref]

76. Véronique Normand, Christian Babski, Steve Benford, Adrian Bullock, Stéphane Carion, Yiorgos Chrysanthou, Nicolas Farcet, Emmanuel Frécon, John Harvey, Nico Kuijpers, Nadia Magnenat-Thalmann, Soraia Raupp-Musse, Tom Rodden, Mel Slater, Gareth Smith, Anthony Steed, Daniel Thalmann, Jolanda Tromp, Martin Usoh, Gidi Van Liempd, Nicos Kladias. 1999. The COVEN Project: Exploring Applicative, Technical, and Usage Dimensions of Collaborative Virtual Environments. Presence: Teleoperators and Virtual Environments 8:2, 218-236. [Abstract] [PDF] [PDF Plus]

77. Stella Mills, Jan Noyes. 1999. Virtual reality: an overview of User-related Design Issues. Interacting with Computers 11:4, 375-386. [Crossref]

78. Jonathan Freeman, S. E. Avons, Don E. Pearson, Wijnand A. IJsselsteijn. 1999. Effects of Sensory Information and Prior Experience on Direct Subjective Ratings of Presence. Presence: Teleoperators and Virtual Environments 8:1, 1-13. [Abstract] [PDF] [PDF Plus]

79. Mel Slater, John McCarthy, Francesco Maringelli. 1998. The Influence of Body Movement on Subjective Presence in Virtual Environments. Human Factors: The Journal of the Human Factors and Ergonomics Society 40:3, 469-477. [Crossref]

80. Chuan-Fong (Eric) Shih. 1998. Conceptualizing consumer experiences in cyberspace. European Journal of Marketing 32:7/8, 655-663. [Crossref]

81. 1998. General Reviews of Virtual Reality and Neuropsychology. CyberPsychology \& Behavior 1:4, 413-425. [Crossref]

82. MILTON P. HUANG, JOSEPH HIMLE, KLAUS-PETER BEIER, NORMAN E. ALESSI. 1998. Challenges of Recreating Reality in Virtual Environments. CyberPsychology \& Behavior 1:2, 163-168. [Crossref]

83. Mel Slater, Sylvia Wilbur. 1997. A Framework for Immersive Virtual Environments (FIVE): Speculations on the Role of Presence in Virtual Environments. Presence: Teleoperators and Virtual Environments 6:6, 603-616. [Abstract] [PDF] [PDF Plus]

84. JOHN R. WILSON. 1997. Virtual environments and ergonomics: needs and opportunities. Ergonomics 40:10, 1057-1077. [Crossref]

85. Taeyong Kim, Frank Biocca. 1997. Telepresence via Television: Two Dimensions of Telepresence May Have Different Connections to Memory and Persuasion.[1]. Journal of Computer-Mediated Communication 3:2, 0-0. [Crossref]

86. Hong Hua, Chunyu Gao, F. Biocca, J.P. Rolland. An ultra-light and compact design and implementation of head-mounted projective displays 175-182. [Crossref]

87. P. Freedman, P. MacKenzie, J.-F. Lapointe. A computer-based training environment for forestry telemanipulation 1826-1831. [Crossref] 